\title{
The effect of different processing, injection molding (IM) and fused deposition modeling (FDM), on the environmental stress cracking (ESC) behavior of filled and unfilled polycarbonate $(\mathrm{PC})$
}

\author{
M. Z. Huang ${ }^{1}$, J. Nomai $^{1}$, A. K. Schlarb ${ }^{1,2,3^{*}}$ \\ ${ }^{1}$ Chair of Composite Engineering (CCe), Technische Universität Kaiserslautern (TUK), Gottlieb-Daimler-Str. Bld. 44, \\ 67663 Kaiserslautern, Germany \\ ${ }^{2}$ Research Center OPTIMAS, Technische Universität Kaiserslautern (TUK), 67663 Kaiserslautern, Germany \\ ${ }^{3}$ Qingdao University of Science \& Technology, 266042 Qingdao, China
}

Received 19 May 2020; accepted in revised form 21 July 2020

\begin{abstract}
The effect of crack propagation management by using a fused deposition modeling (FDM) technique on the environmental stress cracking (ESC) behavior of neat polycarbonate (PC) and $\mathrm{PC}$ with $1 \mathrm{vol} \% \mathrm{SiO}_{2}$ nanocomposites were investigated. The results demonstrate that the crack growth behavior of materials and their ESC resistance are strongly dependent on the printing direction. The ESC resistance and failure time of an FDM print-on injection-molded specimen exhibit the greatest values when the printing direction parallels to the load direction. Comparative analyses of the fracture surfaces reveal that the excellent stress cracking resistance can contribute to favorable stress and load distribution at the crack front area, where the printed continuous strands in alignment with the load can efficiently carry and transfer it. However, the degree of ESC improvement by managing the direction of craze/crack propagation via printing direction is more pronounced in neat $\mathrm{PC}$ than those of $\mathrm{PC}-\mathrm{SiO}_{2}$ nanocomposites.
\end{abstract}

Keywords: nanocomposites, polycarbonate (PC), fused deposition modeling (FDM), environmental stress cracking (ESC), fracture behavior

\section{Introduction}

Additive manufacturing or 3D printing technologies has been continuously developed in the past three decades. Specifically, an extrusion-based additive manufacturing technology, so-called fused deposition modeling (FDM) has been widely used as a novel processing technique to design and prototype polymer components in recent years. Compared with conventional subtractive techniques for polymer processing, FDM provides the benefits of moldless direct and flexible production of customized products with complex geometries, which is also highlighted with low investment costs. The process is based on the melting of a thermoplastic filament in a hot die, which deposits polymer strands according to accurately pre-defined path layer by layer. During the process, the polymer strands with a high viscous weld those fully molten strands together to form the layers. Controlling the weld formation as a crucial factor has been well studied [1-8]. This kind of novel technology deposits material in a directional way that results in components with unique anisotropic behavior, which has been observed to obviously impact mechanical properties $[7,9,10]$. There are various commercial available thermoplastics which are successfully applied for the FDM technique, i.e. polylactic 
acid (PLA) [11-13], acrylonitrile butadiene styrene (ABS) [6, 9], polyethylene terephthalate glycol-modified (PETG) [14, 15], polyvinyl alcohol (PVA) [16, 17], polyamide (PA) [18, 19], etc. Besides, an industrial thermoplastic polycarbonate (PC) has gained increasing attention on its manufacture by using FDM technology due to its excellent durability, stability, and transparency [20-25]. Some work on 3D printing with filled polymers has also been published recently [26-30]. It was shown that graphene [26, 27], carbon nanotubes $[28,29]$, and PCL gelatin nanofibers [30] could improve the mechanical properties of polymeric parts produced by FDM.

However, one of the major shortcomings of polymeric materials involves the environmental stress cracking (ESC), which may occur due to the simultaneous action of mechanical stress and chemical contamination during service (e.g., in medical, automotive, marine, and coating applications) [31,32]. Therefore, the ESC of plastics is a serious issue and has been extensively investigated in the last decades. Previous researches have shown that ESC is responsible for approximately $25-30 \%$ of all plastic component failures in service [31, 33, 34]. Most importantly, about $90 \%$ of these failures occur especially in amorphous (glassy) polymers such as polycarbonate (PC), poly(methyl methacrylate) (PMMA), and polysulfone (PSF), where stress-cracking agents can severely diffuse into their molecular network and promotes premature ESC failure via molecular disentanglement [34-36]. Several studies on the ESC failure demonstrated that the ESC behavior of polymers strongly depends on the solvent solubility parameter relative to those of the polymers as well as on the size and shape of the ESC agents [22, 37, 38]. Efforts have been made to improve the ESC behavior by incorporating different functionalities such as glass fibers [35, 39] and organically modified montmorillonite [40]. In particular, our previous research works presented a significant improvement of ESC resistance of $\mathrm{PC}$ nanocomponents in different media by incorporation of nano-sized fillers [33, 36].

In the present study, we prepared compact tension (CT) specimens of PC and its nanocomposite coating by FDM technique aiming to control the environmental stress cracking behavior with respect to the anisotropic properties of FDM manufactured components.

\section{Experimental and methodology}

\subsection{Materials and sample preparation}

A commercial polycarbonate (PC) with Young's modulus $E=2.4 \mathrm{GPa}$ and tensile strength $\sigma=65 \mathrm{MPa}$ (Makrolon 2405, Bayer Materials Science/Covestro AG, Germany) was used as the polymeric matrix in this study. As filler hydrophobic fumed nano-silica $\left(\mathrm{SiO}_{2}\right)$ with a mean particle diameter of $12 \mathrm{~nm}$ (Aerosil R8200 ${ }^{\circledR}$, Evonik Industries AG, Germany) due to the supplier was chosen. The compounding of the $\mathrm{PC}-\mathrm{SiO}_{2}$ nanocomposite was carried out on a co-rotated twin-screw extruder (ZSE 18 MAXX, Leistritz, Nürnberg, Germany) by using a two-step compounding process. Neat polymer and nano-silica particles were first compounded into a masterbatch, which was then diluted to the $1 \mathrm{vol} \%$ nano-silica particle content. The barrel temperature was set from $240^{\circ} \mathrm{C}$ near the hopper to $270^{\circ} \mathrm{C}$ at the die, and the screw speed was kept at $100 \mathrm{rpm}$, respectively. Afterward, the compound granules were fabricated via a filament extruder (Precision 450, 3devo, Netherlands) into filaments with a diameter of $1.7 \mathrm{~mm}$ for use in the FDM print process.

In parallel, the compound granules were also injection-molded via an injection molding machine (Engel victory 80, Engel Austria GmbH, Schwertberg, Austria) into $50 \times 50 \times 4 \mathrm{~mm}^{3}$ sheets. Then, the injectionmolded sheets were milled to $\mathrm{CT}$ specimens with two cavities of each $0.6 \mathrm{~mm}$ depth, which were further filled with three layers of each $0.2 \mathrm{~mm}$ height with different printing directions $\left(0, \pm 45\right.$, and $90^{\circ}$ to applied force $(F)$ direction), as is shown in Figure 1a. For comparison, the entire $\mathrm{CT}$ specimen was printed as a part at $0^{\circ}$ as well (Figure $1 \mathrm{~b}$ ). All the $3 \mathrm{D}$ printing processes were performed on a modified $3 \mathrm{D}$ printer (Ultimaker 2, Ultimaker B.V., Utrecht, Netherlands). An overview of the different materials and processing methods are listed in Table 1. Based on preliminary work we choose the FDM parameters as shown in the lower part of Table 1.

\subsection{Characterizations of the environmental stress cracking behavior}

The ESC experimental set-up is described in detail in our previous study $[33,36]$. The pre-crack was made in the specimens by lightly tapping a fresh razor blade into the bottom of the saw slot. The pre-crack length $\left(a_{0},[\mathrm{~mm}]\right)$ ranged from $0.45<a_{0} / W<0.55$. 

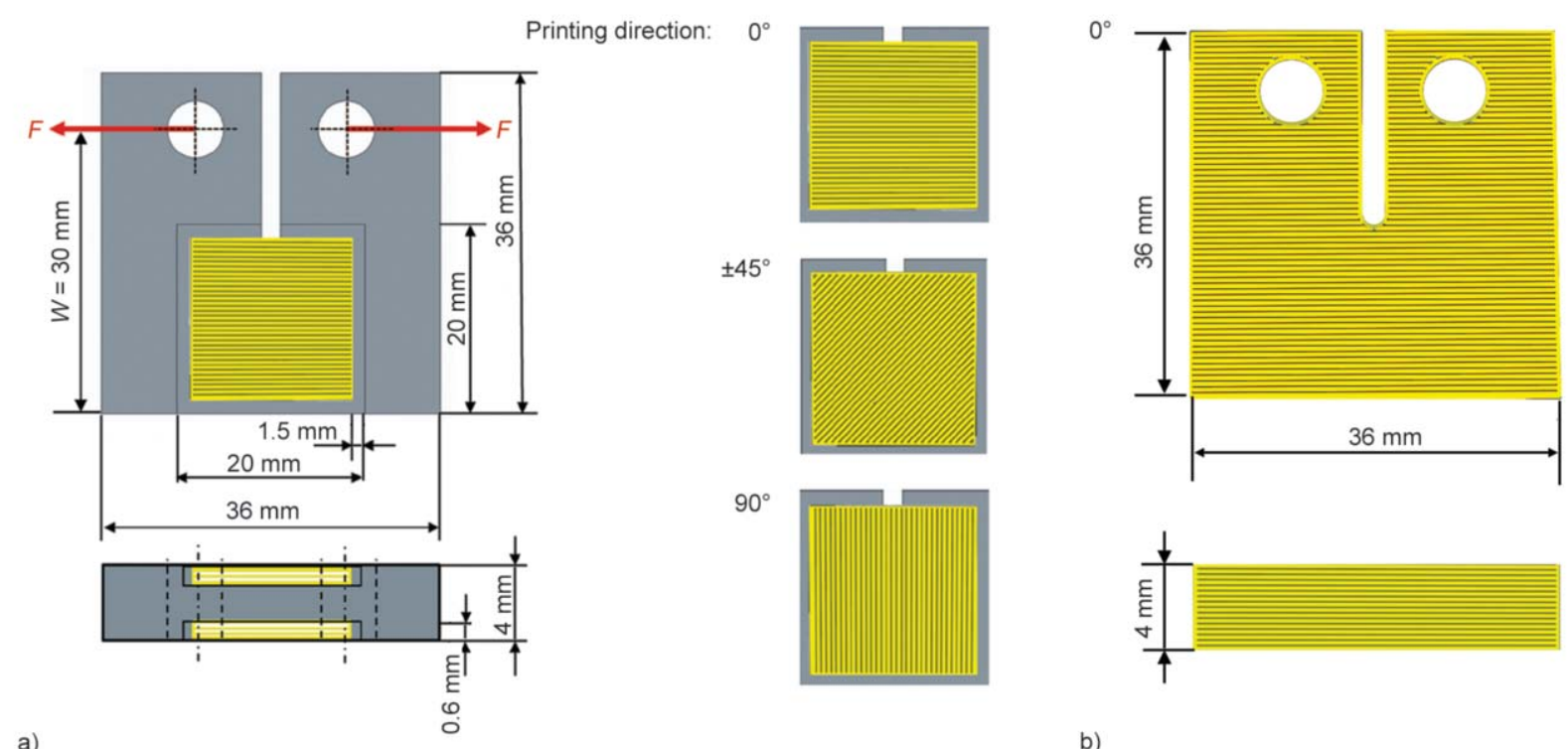

Figure 1. Schematic illustration of (a) FDM print-on injection-molded specimen with different printing directions and (b) fully FDM printed specimen at $0^{\circ}$.

Table 1. An overview of different materials and processing methods of CT-specimens.

\begin{tabular}{|c|c|c|c|c|c|c|}
\hline \multicolumn{7}{|c|}{ Processing methods/Lay-up direction } \\
\hline \multirow[t]{2}{*}{ Designation } & Filler content & $\begin{array}{l}\text { Injection molding } \\
\text { (IM) }\end{array}$ & $\begin{array}{c}\text { Fused deposition modeling } \\
\text { (FDM) }\end{array}$ & \multicolumn{3}{|c|}{$\mathbf{I M}+\mathbf{F D M}$} \\
\hline & [vol\%] & - & $0^{\circ}$ & $0^{\circ}$ & $\pm 45^{\circ}$ & $90^{\circ}$ \\
\hline $\mathrm{PC}$ & 0 & $x$ & $x$ & $x$ & $x$ & $x$ \\
\hline PC-SiO 2 & 1 & $x$ & - & $x$ & - & - \\
\hline \multicolumn{7}{|c|}{ 3D printing parameters } \\
\hline \multirow{2}{*}{\multicolumn{2}{|c|}{ Designation }} & Nozzle temperature & Platform temperature & Printing speed & Layer thickness & Raster width \\
\hline & & {$\left[{ }^{\circ} \mathbf{C}\right]$} & {$\left[{ }^{\circ} \mathbf{C}\right]$} & {$[\mathbf{m m} / \mathbf{s}]$} & {$[\mathrm{mm}]$} & [mm] \\
\hline \multicolumn{2}{|l|}{$\mathrm{PC}$} & 290 & 150 & 10 & 0.2 & 0.3 \\
\hline \multicolumn{2}{|l|}{ PC-SiO 2} & 265 & 150 & 8 & 0.2 & 0.3 \\
\hline
\end{tabular}

Isopropanol (CAS number: 67-63-0) was used as ESC agent [36]. All tests were performed at room temperature $\left(23 \pm 1^{\circ} \mathrm{C}\right)$ and constant load. The development of the macro-crack length and the crack damage area were monitored and documented using a CCD-camera (EOS 1200D, Canon) for further analysis. All the data presented correspond to the average of at least three measurements.

From the captured images, a measured macro-crack length $(a[\mathrm{~mm}])$ was used to determine the transient macro-crack length $(\mathrm{d} a / \mathrm{d} t[\mathrm{~mm} / \mathrm{s}])$ and as an input for calculating the mode I stress intensity factor $\left(K_{\mathrm{I}}\right.$ $\left.\left[\mathrm{MPa} \cdot \mathrm{m}^{1 / 2}\right]\right)$ of the $\mathrm{CT}$ specimen according to the Equation (1):

$K_{\mathrm{I}}=f\left(\frac{a}{W}\right) \cdot\left(\frac{F}{B W^{1 / 2}}\right)$

where $f$ is given by Equation (2):

$$
\begin{aligned}
f\left(\frac{a}{W}\right) & =\left[\frac{2+\frac{a}{W}}{\left(1-\frac{a}{W}\right)^{3 / 2}}\right] \cdot\left[0.866+4.64 \frac{a}{W}-\right. \\
& \left.-13.32\left(\frac{a}{W}\right)^{2}+14.72\left(\frac{a}{W}\right)^{3}-5.6\left(\frac{a}{W}\right)^{4}\right]
\end{aligned}
$$

$F$ is the applied load [N], $B$ and $W$ denote the specimen dimensions 4 and $30 \mathrm{~mm}$, respectively.

After ESC tests, the fracture surface of failed CT specimens was analyzed by using the Keyence confocal 3D laser scanning microscope (VK-X 1000, Germany).

\section{Results and discussion}

The process of stress cracking starts with crazing, which is characterized by the formation of fibrils and microvoids, followed by the failure of some fibrils, the development of macro-voids, and ultimately the progress of a macrocrack. The material orientation 
Table 2. Crack propagation behavior of neat PC with different printing direction in isopropanol.



due to the formation of fibrils and the locally different densities lead to a scattering of incident light in different directions depending on its wavelength. The different shades in front of the crack tip are, therefore, an indicator of the deformation processes in this area. Table 2 shows the deformation area of both injection-molded and FDM-processed neat PC,

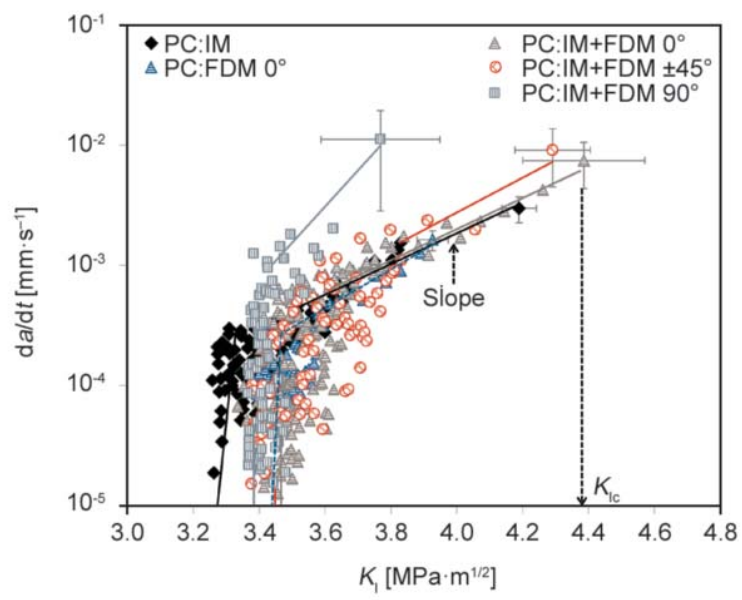

Figure 2. Macro-crack propagation rate as a function of $K_{\mathrm{I}}$ factor of neat PC with different processing methods and printing directions.



which develops in two directions, displaying a similar 'candle flame' pattern in front of the advancing ridge tip. It is interesting to note that the major directions of craze/crack propagation of FDM-processed materials seem to follow the printing direction. A blunting of the micro-crack due to multiple crazing deformations appear in the specimen printed at $0^{\circ}$ to the loading direction. Similar behavior is observed in the specimen printed at $\pm 45^{\circ}$ but on a smaller scale. Conversely, an intense crazing area with only one major direction of deformation, is observed in the specimen printed at $90^{\circ}$ to the loading direction. These different types of deformation areas indicate different dissipation of the fracture energy, thus implying a different fracture mechanism in the isopropanol [41, 42]. As is evident, the crack growth behavior can be controlled by the printing direction in the FDM process.

The effect of the printing direction on the macrocrack propagation rate as a function of the $K_{\mathrm{I}}$ factor of the neat PC is shown in Figure 2, and the average values of critical stress intensity factor $\left(K_{\text {Ic }}\right)$, slope

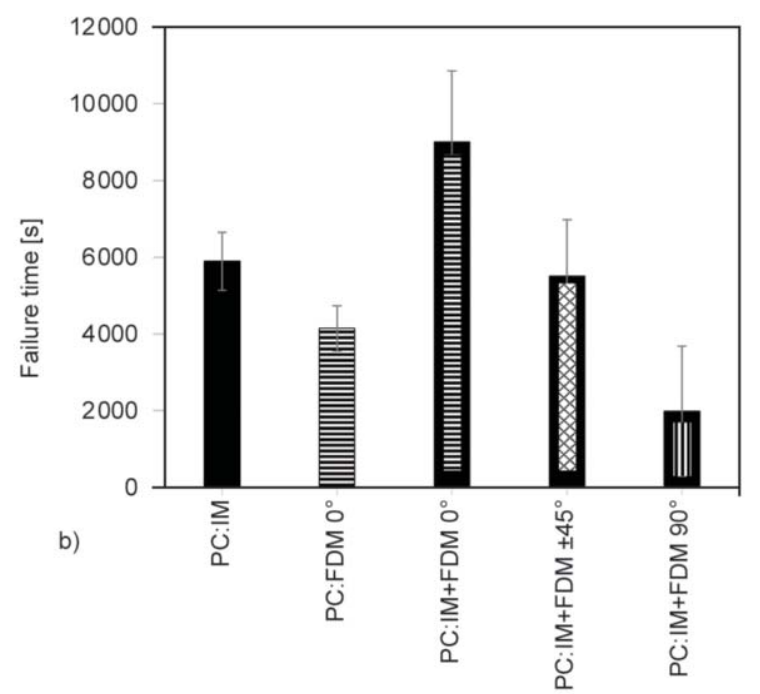

Figure 3. (a) $K_{\mathrm{Ic}}$ and slope in stable crack growth region and (b) failure time of neat PC with different processing methods and printing directions. 
in the stable crack growth region and failure time are shown in Figure 3a and 3b, respectively. As expected, the aforementioned difference in crack growth behavior controlled by the printing direction has a substantial effect on the improvement of ESC resistance and failure time of the materials. The FDM print-on injection molded parts at $0^{\circ}(\mathrm{PC}: \mathrm{IM}+\mathrm{FDM}$ $0^{\circ}$ ) has the highest ESC resistance followed by $\pm 45^{\circ}$ (PC:IM+FDM $\pm 45^{\circ}$ ), as indicated by an increase in the values of $K_{\mathrm{Ic}}$ and a decrease of slope in the stable crack growth region. Accordingly, the service life is prolonged by about $53 \%$ in isopropanol, as compared to injection molded specimens. In contrast, FDM print-on injection molded parts at $90^{\circ}$ (PC:IM+FDM 90 $0^{\circ}$ ) is indeed observed to have the lowest ESC resistance, which agrees well with the reported results of fracture toughness of 3D printed parts $[2,8,41]$. A printed part exhibits poor properties when the applied load is perpendicular to the alignment of the printed strands. Thus, a layer
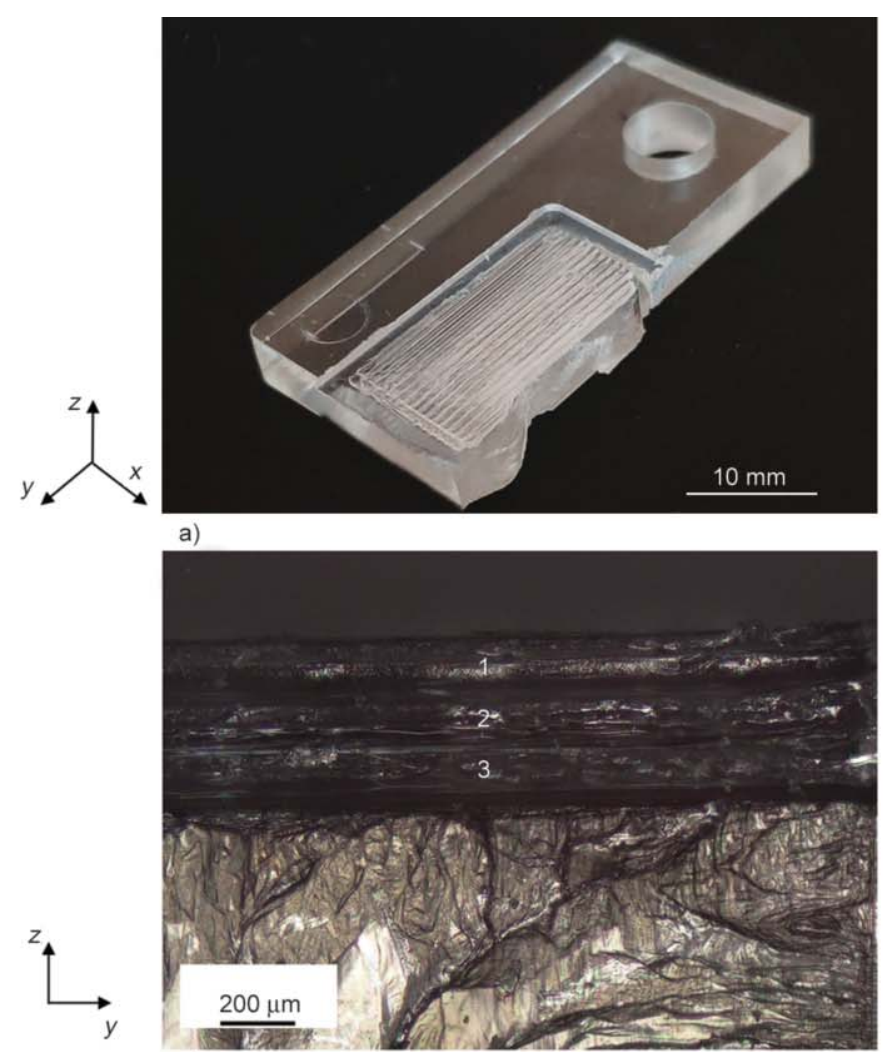

c)
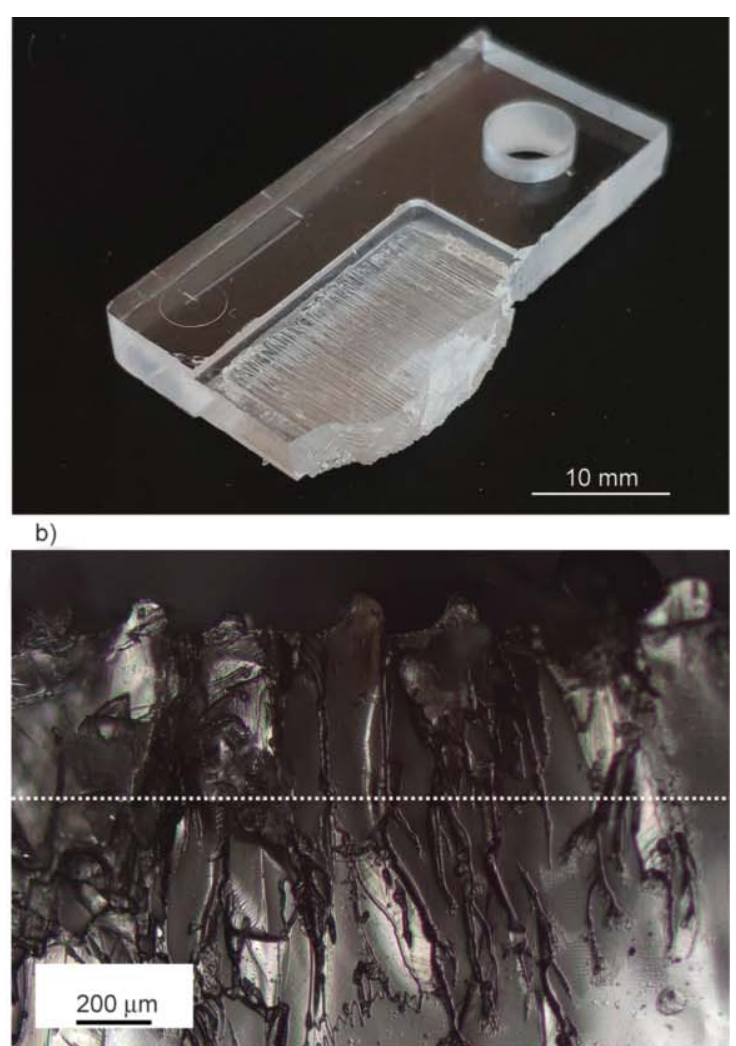

d)

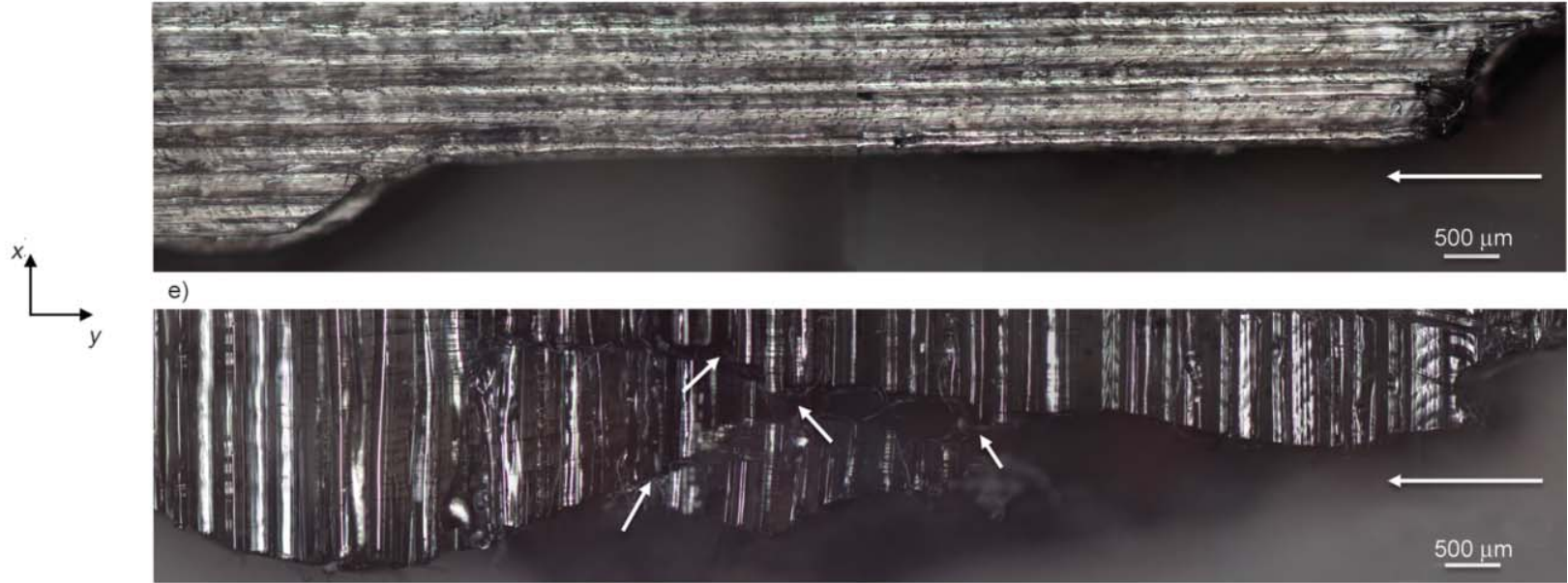

f)

Figure 4. (a) CT-specimens of neat PC with printing direction $90^{\circ}$ and (b) $0^{\circ}$ after ESC tests, (c) fracture surface of $90^{\circ}$-direction and (d) $0^{\circ}$-direction. The number and the dashed line indicate the printed layers and the boundary of printed layers and injection molded specimens, respectively, (e) detail view of crack propagation of $90^{\circ}$-direction and (f) $0^{\circ}$-direction printed layers. 
delamination failure usually occurs at a lower force and promotes faster crack propagation. In addition, full FDM printed parts $(\mathrm{FDM})$ at $0^{\circ}\left(\mathrm{PC}: \mathrm{FDM} 0^{\circ}\right)$ is noticeable to have the lower ESC resistance compared to injection molded specimens (PC:IM).

Fracture mechanisms were characterized by inspecting the fractured surface and the damaged zone around the crack front in the CT specimens. As is shown in Figure 4, CT-specimens of neat PC with printing direction $90^{\circ}$ exhibit quite smooth fractured surface compared to those of $0^{\circ}$-direction (Figure $4 \mathrm{a}$ and $4 \mathrm{~b}$ ). A close view of the fractured surface clearly demonstrates that the printed layers at $90^{\circ}$ still keep in original form with a visible weld line, where smooth and featureless surface indicate weak interfacial welding between strands to resist crack propagation, resulting in a poor ESC performance (Figure $4 \mathrm{c}$ ). In contrast, a high level of plastic deformations took place at the printed layers in $0^{\circ}$-direction, as can be seen in Figure 4d. The deformation of the specimen due to crazing of the polymer, which is believed to be important for absorbing energy to prevents fracture. It is also worthy of noting that the specimen at $0^{\circ}$-direction exhibits a kind of arbitrary fracture performance with respect to crack propagation, as indicated by the white arrows in Figure 4f. It is revealed that the force starts breaking printed strands closed to crack tip in sequence along the direction of crack propagation, absorbing more fracture energy over a larger area, which results in a higher ESC resistance. All the above-mentioned crack deflections between the strands and the weld areas between printed and injection-molded parts contributed to the better properties of the specimens manufactured in a combination of injection molding and $3 \mathrm{D}$ printing $\left(\mathrm{IM}+\mathrm{FDM} 0^{\circ}\right)$. Conversely, crack propagation in the specimen at $90^{\circ}$-direction took place straightly along the weld line between strands (Figure 4e), where the delamination failure of 3D printed part usually occurs due to the weak weld formation. As a result, faster crack propagation was exhibited, as discussed beforehand.
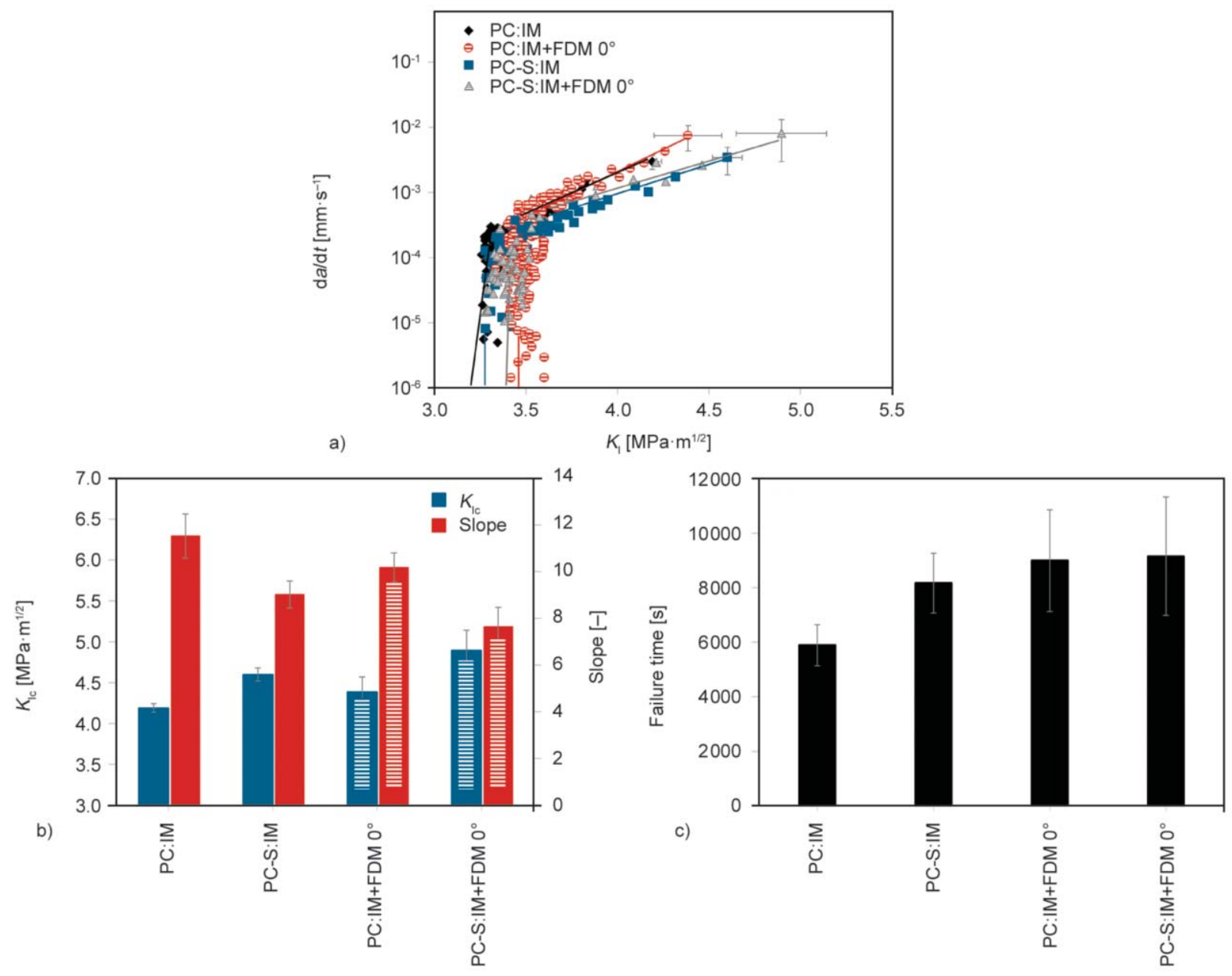

Figure 5. (a) Macro-crack propagation rate as a function of $K_{\mathrm{I}}$ factor, (b) $K_{\mathrm{Ic}}$ and slope in the stable crack growth region, and (c) failure time of neat PC and PC-S nanocomposite with different processing methods. 
A successful improvement in ESC resistance by controlling the direction of craze/crack propagation via printing direction is also found in $\mathrm{PC}$ nanocomposites filled with 1 vol\% nano- $\mathrm{SiO}_{2}$, as can be seen in Figure 5. The FDM print-on injection-molded $\mathrm{PC}-\mathrm{SiO}_{2}$ nanocomposite at $0^{\circ}\left(\mathrm{PC}-\mathrm{S}: \mathrm{IM}+\mathrm{FDM} 0^{\circ}\right)$, exhibits greater ESC resistance than that of the injected specimen (PC-S:IM). As it can be clearly observed that there is a significant improvement in the $K_{\text {Ic }}$ and a reduction in the crack propagation rate with the FDM print-on injection-molded nanocomposite. However, the degree of ESC improvement for the PC-based nanocomposites is less than those of neat PC.

Concerning the effect of nanofiller, it is interesting to note that the incorporation of nano- $\mathrm{SiO}_{2}$ to $\mathrm{PC}$ causes a significant reduction in the crack propagation rate and prolongs the onset period of catastrophic failure $\left(K_{\mathrm{Ic}}\right)$, and thus increases the ESC resistance and the failure time of the materials. The great improvement in the ESC resistance is achieved due to the formation of dissipative energy structures (cavities, debonding, and localized micro-deformation) induced by nanoparticles, which results in effective energy dissipation during the deformation process $[33,36]$. Therefore, it can be suggested that the addition of nanoparticles to PC is an alternative method for controlling the crack propagation behavior of the materials.

\section{Conclusions}

A comparison of the stress crack resistance of injection molded and 3D printed samples shows clear differences. Although the critical stress intensity factor for mode I loading is somewhat higher for 3D-printed samples, the significantly higher crack speed with the same stress intensity leads to an earlier failure of 3D-printed samples.

If injection molding is combined with local deposition of strands via 3D printing, the results depend on the lay-up strategy. While a lay-up direction parallel to the direction of crack propagation leads to relatively poor properties, this behavior improves with $\pm 45^{\circ}$ deposition of the strands. The best properties are achieved when the strands are placed in $3 \mathrm{D}$ printing perpendicular to the direction of crack propagation. In this case, the combination leads to a significantly higher stress crack resistance even compared with injection-molded samples. This behavior is visible both with unfilled and with $\mathrm{SiO}_{2}$ filled polycarbonate, even if the effect is stronger in neat polycarbonate.

Therefore, the combination of injection molding with a local filling of cavities by means of 3D printing therefore seems to be an effective approach to control the properties of a component by processing alone.

The behavior is crucially determined by the quality of the weld seams between the 3D printed strands. While the weld lines with crack growth parallel to the direction of deposition prove to be a weak point, the better deformability with a load parallel to the direction of deposit and thus a perpendicular crack growth leads to a significantly higher resistance to stress cracking. The particularly good properties of the samples produced in a combination of injection molding and $3 \mathrm{D}$ printing are due to crack deflections between the strands and the weld areas between printed and injection-molded areas.

\section{Acknowledgements}

The authors are grateful to Covestro AG, Leverkusen, and Evonik Industries AG, Hanau-Wolfgang, for the supply of the materials.

\section{References}

[1] Bhalodi D., Zalavadiya K., Gurrala P. K.: Influence of temperature on polymer parts manufactured by fused deposition modeling process. Journal of the Brazilian Society of Mechanical Sciences and Engineering, 41, 113/1-113/11 (2019). https://doi.org/10.1007/s40430-019-1616-Z

[2] Davis C. S., Hillgartner K. E., Han S. H., Seppala J. E.: Mechanical strength of welding zones produced by polymer extrusion additive manufacturing. Additive Manufacturing, 16, 162-166 (2017).

https://doi.org/10.1016/j.addma.2017.06.006

[3] Costa S. F., Duarte F. M., Covas J. A.: Estimation of filament temperature and adhesion development in fused deposition techniques. Journal of Materials Processing Technology, 245, 167-179 (2017). https://doi.org/10.1016/j.jmatprotec.2017.02.026

[4] Sun Q., Rizvi G. M., Bellehumeur C. T., Gu P.: Experimental study of the cooling characteristics of polymer filaments in FDM and impact on the mesostructures and properties of prototypes. in '2003 International Solid Freeform Fabrication Symposium. Austin, USA' 313323 (2003). https://doi.org/10.26153/tsw/5566

[5] Gurrala P. K., Regalla S. P.: Part strength evolution with bonding between filaments in fused deposition modelling. Virtual and Physical Prototyping, 9, 141-149 (2014). https://doi.org/10.1080/17452759.2014.913400 
[6] Seppala J. E., Migler K. D.: Infrared thermography of welding zones produced by polymer extrusion additive manufacturing. Additive Manufacturing, 12, 71-76 (2016). https://doi.org/10.1016/j.addma.2016.06.007

[7] McIlroy C., Olmsted P. D.: Disentanglement effects on welding behaviour of polymer melts during the fusedfilament-fabrication method for additive manufacturing. Polymer, 123, 376-391 (2017).

https://doi.org/10.1016/j.polymer.2017.06.051

[8] Seppala J. E., Hoon H. S., Hillgartner K. E., Davis C. S., Migler K. B.: Weld formation during material extrusion additive manufacturing. Soft Matter, 13, 6761-6769 (2017). https://doi.org/10.1039/c7sm00950j

[9] Ahn S-H., Montero M., Odell D., Roundy S., Wright P. K.: Anisotropic material properties of fused deposition modeling ABS. Rapid Prototyping Journal, 8, 248-257 (2002).

https://doi.org/10.1108/13552540210441166

[10] Zaldivar R. J., Witkin D. B., McLouth T., Patel D. N., Schmitt K., Nokes J. P.: Influence of processing and orientation print effects on the mechanical and thermal behavior of 3D-printed ULTEM ${ }^{\circledR} 9085$ material. Additive Manufacturing 13, 71-80 (2017). https://doi.org/10.1016/j.addma.2016.11.007

[11] Yu W. W., Zhang J., Wu J. R., Wang X. Z., Deng Y. H.: Incorporation of graphitic nano-filler and poly(lactic acid) in fused deposition modeling. Journal of Applied Polymer Science, 134, 44703/1-44703/11 (2017). https://doi.org/10.1002/app.44703

[12] Senatov F. S., Niaza K. V., Zadorozhnyy M. Y., Maksimkin A. V., Kaloshkin S. D., Estrin Y. Z.: Mechanical properties and shape memory effect of 3D-printed PLA-based porous scaffolds. Journal of the Mechanical Behavior of Biomedical Materials, 57, 139-148 (2016). https://doi.org/10.1016/j.jmbbm.2015.11.036

[13] Ferreira R. T. L., Amatte I. C., Dutra T. A., Bürger D.: Experimental characterization and micrography of $3 \mathrm{D}$ printed PLA and PLA reinforced with short carbon fibers. Composites Part B: Engineering, 124, 88-100 (2017).

https://doi.org/10.1016/j.compositesb.2017.05.013

[14] Durgashyam K., Indra Reddy M., Balakrishna A., Satyanarayana K.: Experimental investigation on mechanical properties of PETG material processed by fused deposition modeling method. Materialstoday: Proceedings, 18, 2052-2059 (2019). https://doi.org/10.1016/j.matpr.2019.06.082

[15] Szykiedans K., Credo W., Osiński D.: Selected mechanical properties of PETG 3D prints. Procedia Engineering, 177, 455-461 (2017).

https://doi.org/10.1016/j.proeng.2017.02.245
[16] Goyanes A., Kobayashi M., Martínez-Pacheco R., Gaisford S., Basit A. W.: Fused-filament 3D printing of drug products: Microstructure analysis and drug release characteristics of PVA-based caplets. International Journal of Pharmaceutics, 514, 290-295 (2016).

https://doi.org/10.1016/j.ijpharm.2016.06.021

[17] Tagami T., Fukushige K., Ogawa E., Hayashi N., Ozeki T.: 3D printing factors important for the fabrication of polyvinylalcohol filament-based tablets. Biological and Pharmaceutical Bulletin, 40, 357-364 (2017).

https://doi.org/10.1248/bpb.b16-00878

[18] Liao G., Li Z., Cheng Y., Xu D., Zhu D., Jiang S., Guo J., Chen X., Xu G., Zhu Y.: Properties of oriented carbon fiber/polyamide 12 composite parts fabricated by fused deposition modeling. Materials and Design, 139, 283-292 (2018).

https://doi.org/10.1016/j.matdes.2017.11.027

[19] Mostafa K. G., Montemagno C., Qureshi A. J.: Strength to cost ratio analysis of FDM nylon 12 3D printed parts. Procedia Manufacturing, 26, 753-762 (2018).

https://doi.org/10.1016/j.promfg.2018.07.086

[20] Bartolai J., Simpson T. W., Xie R.: Predicting strength of additively manufactured thermoplastic polymer parts produced using material extrusion. Rapid Prototyping Journal, 24, 321-332 (2018). https://doi.org/10.1108/RPJ-02-2017-0026

[21] Reyes-Rodríguez A., Dorado-Vicente R., Mayor-Vicario R.: Dimensional and form errors of PC parts printed via fused deposition modelling. Procedia Manufacturing, 13, 880-887 (2017). https://doi.org/10.1016/j.promfg.2017.09.149

[22] Arnold J. C.: The influence of liquid uptake on environmental stress cracking of glassy polymers. Materials Science and Engineering: A, 197, 119-124 (1995). https://doi.org/10.1016/0921-5093(94)09759-3

[23] Yadav R., Naebe M., Wang X., Kandasubramanian B.: Structural and thermal stability of polycarbonate decorated fumed silica nanocomposite via thermomechanical analysis and in-situ temperature assisted SAXS. Scientific Reports, 7, 7706/1-7706/11 (2017). https://doi.org/10.1038/s41598-017-08122-7

[24] Reich M. J., Woern A. L., Tanikella N. G., Pearce J. M.: Mechanical properties and applications of recycled polycarbonate particle material extrusion-based additive manufacturing. Materials, 12, 1642/1-1642/18 (2019). https://doi.org/10.3390/ma12101642

[25] Hill N., Haghi M.: Deposition direction-dependent failure criteria for fused deposition modeling polycarbonate. Rapid Prototyping Journal, 20, 221-227 (2014). https://doi.org/10.1108/RPJ-04-2013-0039

[26] Mansour M., Tsongas K., Tzetzis D.: Measurement of the mechanical and dynamic properties of $3 \mathrm{D}$ printed polylactic acid reinforced with graphene. Polymer-Plastics Technology and Materials, 58, 1234-1244 (2019). https://doi.org/10.1080/03602559.2018.1542730 
[27] Dul S., Fambri L., Pegoretti A.: Fused deposition modelling with ABS-graphene nanocomposites. Composites Part A: Applied Science and Manufacturing, 85, 181-191 (2016).

https://doi.org/10.1016/j.compositesa.2016.03.013

[28] Sanatgar R. H., Campagne C., Nierstrasz V.: Investigation of the adhesion properties of direct 3D printing of polymers and nanocomposites on textiles: Effect of FDM printing process parameters. Applied Surface Science, 403, 551-563 (2017).

https://doi.org/10.1016/j.apsusc.2017.01.112

[29] Berretta S., Davies R., Shyng Y. T., Wang Y., Ghita O.: Fused deposition modelling of high temperature polymers: Exploring CNT PEEK composites. Polymer Testing, 63, 251-262 (2017).

https://doi.org/10.1016/j.polymertesting.2017.08.024

[30] Naghieh S., Badrossamay M., Foroozmehr E., Kharaziha M.: Combination of PLA micro-fibers and PCL-gelatin nano-fibers for development of bone tissue engineering scaffolds. International Journal of Swarm Intelligence and Evolutionary Computation, 6, 1000150/11000150/4 (2017).

https://doi.org/10.4172/2090-4908.1000150

[31] Schlarb A. K.: Determining resistance to environmental stress cracking in luer fittings. Medical Device Technology, 13, 30-34 (2002).

[32] Saharudin M. S., Atif R., Shyha I., Inam F.: The degradation of mechanical properties in polymer nano-composites exposed to liquid media - A review. RSC Advances, 6, 1076-1089 (2016).

https://doi.org/10.1039/c5ra22620a

[33] Lin L., Schlarb A. K.: A study on environmental stress cracking in nano- $\mathrm{SiO}_{2}$-filled polycarbonate. Journal of Materials Science, 47, 6614-6620 (2012). https://doi.org/10.1007/s10853-012-6597-6

[34] Altstädt V.: The influence of molecular variables on fatigue resistance in stress cracking environments. in 'Intrinsic molecular mobility and toughness of polymers II' (ed.: Kausch H-H.) Springer, Berlin, Vol 188, 105-152 (2005).

https://doi.org/10.1007/b136975
[35] Robeson L. M.: Environmental stress cracking: A review. Polymer Engineering and Science, 53, 453-467 (2013). https://doi.org/10.1002/pen.23284

[36] Nomai J., Schlarb A. K.: Environmental stress cracking (ESC) resistance of poly-carbonate/ $\mathrm{SiO}_{2}$ nanocomposites in different media. Journal of Applied Polymer Science, 134, 45451/1-45451/6 (2017).

https://doi.org/10.1002/app.45451

[37] Grein C.: Toughness of neat, rubber modified and filled $\beta$-nucleated polypropylene: From fundamentals to applications. in 'Intrinsic molecular mobility and toughness of polymers II' (ed.: Kausch H-H.) Springer, Berlin, Vol 188, 43-104 (2005).

https://doi.org/10.1007/b136972

[38] Grassi V. G., dal Pizzol M. F., Forte M. M. C., Amico S. C.: Influence of small rubber particles on the environmental stress cracking of high impact polystyrene. Journal of Applied Polymer Science, 121, 1697-1706 (2011). https://doi.org/10.1002/app.33794

[39] Pons N., Bergeret A., Benezet J-C., Ferry L., Fesquet F.: An environmental stress cracking (ESC) test to study the ageing of biopolymers and biocomposites. Polymer Testing, 30, 310-317 (2011).

https://doi.org/10.1016/j.polymertesting.2010.11.015

[40] Bonnia N. N., Ahmad S. H., Surip S. N., Nurul S. S., Azlina H. N., Anuar H.: Mechanical properties and environmental stress cracking resistance of rubber toughened polyester/clay composite. Advanced Materials Research, 576, 318-321 (2012).

https://doi.org/10.4028/www.scientific.net/AMR.576.318

[41] McLouth T. D., Severino J. V., Adams P. M., Patel D. N., Zaldivar R. J.: The impact of print orientation and raster pattern on fracture toughness in additively manufactured ABS. Additive Manufacturing, 18, 103-109 (2017). https://doi.org/10.1016/j.addma.2017.09.003

[42] Bao R-Y., Cao J., Liu Z-Y., Yang W., Xie B. H., Yang M-B: Towards balanced strength and toughness improvement of isotactic polypropylene nanocomposites by surface functionalized graphene oxide. Journal of Materials Chemistry A, 2, 3190-3199 (2014). https://doi.org/10.1039/c3ta14554at 